Prefabrication of substructures for single-detached dwellings on reactive soils: a review of existing systems and design challenges

Bertrand Teodosio $^{a *}$, K.B.K. Shanaka ${ }^{\mathrm{a}}$, P. Mendis ${ }^{\mathrm{a}}$ and D. Heath ${ }^{\mathrm{a}}$

${ }^{a}$ Infrastructure Engineering, The University of Melbourne, Parkville, Australia 


\title{
Prefabrication of substructures for single-detached dwellings on reactive soils: a review of existing systems and design challenges
}

\author{
The possible thriving Australian construction industry for residential structures \\ has been hindered by skilled labour shortage and eventually triggered housing \\ shortage and affordability crisis. Prefabrication is a promising method to alleviate \\ issues related to housing shortage and affordability by reducing material wastage, \\ construction delays, weather impacts, unexpected costs, skilled labour \\ dependence and construction risks. The full potential of prefabricated \\ construction is yet to be realised in part due to most of developments being \\ focused on its superstructure. Prefabricated substructures should conform with \\ the Ultimate Limit State (i.e., strength capacity) and the Serviceability Limit \\ State (i.e., allowable deformation and damage) stated in the Australian Standards. \\ One of the important considerations is the impact of reactive soils to residential \\ structures that causes financial damages globally. These reactive soils are clayey \\ grounds that change significantly in volume due to change in soil moisture. Due \\ to the initiatives to alleviate issues of housing crisis, skilled labour shortage and \\ unpredictable house damage, it is necessary to review the existing available \\ substructures suitable for single-detached dwellings on reactive soils and to \\ evaluate the necessary considerations and challenges in developing prefabricated \\ substructures. This review will help understand the present state of the design and \\ construction industry and the efforts of inventors and designers to reduce \\ damages due the shrinking and swelling ground movements. This review also \\ guides product developers to design systems having robust performance without \\ compromising practicality.
}

Keywords: Substructures; foundation design; single-detached dwellings; reactive soils; prefabricated construction; design for manufacturing and assembly; housing crisis; skilled labour shortage

\section{Introduction}

The positive Australian economic environment and population increase have led to a growing demand for residential structures. The Australian property market for dwellings has seen consistent increases of approximately 3\% per annum since 1970s (Stapledon, 2010). The average total number of dwelling commencements from 2001 to 
present is on average 150,000 per year (Australian Bureau of Statistics, 2017) and yet, the cumulative housing shortage is still around 220,000 (Cannington, 2017). This strong demand for houses and acceptable rate of dwelling completion has been countered by a shortage of skilled trades which has constrained sustainable growth in the housing industry (Lewis, 2017). In turn, there have been price increases, material and labour shortages, issues related to construction quality and delays (Yu et al., 2008).

Prefabricated housing offers a solution for these challenges by building houses with less waste, greater certainty for building costs, improved site safety, controlled quality of materials and workmanship, and shorter construction cycle time (Lichtenberg, 2006). Furthermore, prefabrication only requires in-situ assembly reducing the necessity for skilled trades for site preparation, general building, bricklaying, carpentry, ceramic tiling, joinery, plastering, other trades (Gibb, 1999).

Prefabrication, the method of constructing off-site and then transporting and assembling on-site, has been adopted for the superstructure of residential houses for many years (Yu et al., 2008). Significant advancements in the design and construction of superstructures have increased the number of prefabricated houses built in most developed countries like Japan and the United States of America (Barlow and Ozaki, 2005; Song et al., 2005). Safety of prefabricated elements has also been globally investigated to assure the robustness of superstructures (Friedman, 1992). Most innovations have been focusing on the superstructure of houses and conventional methods for the construction of the substructure of houses are still the preferred approaches (Pujadas Gispert, 2016). Construction of substructures using traditional castin-place concrete causes site disturbance, which leads to environmental degradation and construction delays (Nelson, 2008). 
The prefabrication of substructures has the potential to have a positive impact on the housing industry by improving construction quality, improving sustainability, reducing construction delays, reducing the industry's reliance on skilled labour, and increasing certainty in project expenses (Monash University, 2017).

To date there has been minimal development of prefabricated substructure solutions that are suitable for low-rise single-detached dwellings on reactive soils. Prefabricated substructures should conform with the Ultimate Limit State (i.e., strength capacity) and the Serviceability Limit State (i.e., allowable deformation and damage) stated in the Australian Standards. One of the important considerations is the impact of reactive soils to lightweight structures, such as single-detached dwellings and pavements, since these are more susceptible to experience the shrink and swell movements caused by the decrease and increase in soil moisture content between seasonal changes and root water uptake of vegetation (Teodosio et al., 2018). These shrink-swell movements can cause damage requiring minor repair to major overhaul to the entire lightweight structures ( $\mathrm{Li}$ and Cameron, 2002). The cost of damage due to the change in volume of reactive soils amounts to billions of dollars annually worldwide (Jones and Jefferson, 2012; Miao et al., 2012; Skinner et al., 1998; Cameron et al., 1987; Krohn and Slosson, 1980).

Due to the initiatives to alleviate issues of housing crisis and to minimise unpredictable house damage, it is necessary to review existing available substructures suitable for single-detached dwellings on reactive soils that will provide as benchmarks to develop prefabricated substructures considering challenges in design and implementation. This review will help understand the present state of the design and construction industry and the efforts of inventors and designers to reduce damages due the shrinking and swelling ground movements of reactive soils. This review also guides 
product developers to design systems having robust performance without compromising practicality for a better market uptake of prefabricated substructures for dwellings.

\section{Existing substructures for single-detached dwellings}

\section{Conventional substructures}

The Australian Standard 2870: Residential slabs and footings (Standards Australia, 2011a) sets out the criteria for site classification for reactive soils and the design and construction of typical substructures used in Australian residentials. The substructures being used in practice for houses are waffle raft and stiffened raft, which are both slab substructures. The site class is assigned base on the characteristic surface movement $\left(y_{s}\right)$ due to expansion and shrink of reactive clayey soils (Table 1), calculated using

$$
y_{S}=\frac{1}{100} \sum_{n=1}^{N}\left(I_{p t} \overline{\Delta u} h\right)_{n}=\frac{1}{100} \sum_{n=1}^{N}\left(\alpha I_{p s} \overline{\Delta u} h\right)_{n}
$$

where $I_{p t}$ is the instability index $(\mathrm{pF}), \Delta u$ is the average soil suction change over the layer thickness $(\mathrm{pF}), \alpha$ is the lateral restraint factor, $I_{p s}$ is the soil shrinkage index $(\% / \mathrm{pF}), h$ is the layer thickness, and $N$ is the number of soil layers. The specification of a suitable substructure (depth of the beams and internal ribs, size and amount of reinforcement) depends on the classification of sites and the nature of the superstructure (e.g. full masonry, articulated masonry, brick veneer, cladding, weatherboard, etc.). For expected surface characteristic movement and for given wall system, differential settlement is limited by selecting adequate stiffness for substructures so that superstructures will have permissible damage levels.

One of the most commonly used substructures in Australia is the waffle raft due to the advantage in construction and cost (Figure 1). It is comprised of closely spaced 
beams and voids created by formed voids (e.g. Expanded Polystyrene (EPS), polypropylene (PP), polyethylene (PE) or card board formwork). The spacing of internal beams is approximately $1.1 \mathrm{~m}$ centre-to-centre with an internal beam width equal to $110 \mathrm{~mm}$. The internal and edge beams vary depending on the house wall system (i.e. clad frame, articulated masonry veneer, masonry veneer, articulated full masonry and full masonry) and its site classification (Class A, S M, H1, H2 and E). A minimum of $300 \mathrm{~mm}$ wide edge beam is required for full masonry, masonry veneer and articulated masonry veneer systems while $110 \mathrm{~mm}$ wide edge beams are required for cladding frames. The internal and edge beam depths range from $300 \mathrm{~mm}$ to 1100 $\mathrm{mm}$ as specified in AS 2870. Beam excavation is not necessary since the system is installed on-ground. The slab thickness of waffle rafts is typically thinner $(85 \mathrm{~mm})$ than stiffened slabs $(100 \mathrm{~mm})$.

The construction of waffle raft starts with ground levelling since waffle raft needs to be laid out on a levelled surface. Due to this, a waffle raft system is commonly used in sites that do not have significant slopes (e.g. sites requiring cut and fill). The construction of substructures depends on the floor area, complexity of the design and available skilled workers. The waffle pods made of EPS are simply laid out for half a day and takes two to four hours for steel reinforcements placing and concreting. Curing typically lasts for three to seven days and installation of superstructures commences after seven to fourteen days. It is worth noting that curing of concrete commonly takes around twenty-eight days, however, since fixing timber frame does not have significant load, structural engineers or builders specify earlier superstructure construction commencements. Thus, the total time to construct a waffle raft is approximately between five and ten days. 
Waffle rafts are not usually advised to be installed in areas with high cyclonic winds since the whole substructure is resting on the ground without anchors and there is limited resistance to uplift forces.

Another common substructure is a stiffened raft, comprised of reinforced concrete beams and slabs across the entire floor plan (Figure 2). Excavation is necessary, and this is dependent on the depth of beams and slab thickness. The excavation for the internal and edge beams commonly takes around one and a half to three days depending on how many skilled labours are working on a site. Formwork is then installed that lasts for half to a full day, and concrete is poured in-situ lasting for two to four hours. The slab is usually raised above the ground level to ensure that stormwater will not flow into the house and cause damage. The stiffened raft requires significant site preparation including grading, excavation, formwork setup and concrete curing. The total period to construct a stiffened slab extends from seven to fourteen days or longer.

Slab substructures (i.e., waffle raft and stiffened raft) are advantageous in sites where the depths of reactive soils make costs of deep substructures prohibitive and basements are not used. In extreme reactive and problematic sites, a pier-and-beam or a pier-and-slab system are designed in accordance with engineering principles (Appendix G, AS 2870-2011 of Standards Australia, 2011). These deep substructures incorporate bored or bulk piers or piles and reinforced concrete beams or slabs, which eliminate effects of heaving soil through isolation. Pier-and-beam or Pier-and-slab systems can reduce the total and the differential settlement of houses by transferring applied structure loads to a deeper and stronger subsurface layer taking advantage of the skin friction of soils. The depth-to-width ratios of these systems are equal to or greater than 5.0. These systems are more expensive than slab systems (i.e., waffle rafts and stiffened 
rafts) and cause greater site disturbance requiring skillful installations using heavy and specialised equipment.

Isolated and strip footings are not commonly used in sites with moderate to highly reactive soils due to the non-uniform global behaviour of these types of substructures (Department of the Army USA, 1983). Isolated and strip footings are often constructed in more stable sites where the predicted movement, $y_{s}$, is less than 15 $\mathrm{mm}$.

Block masonry piers or pads with ground anchors are also used as substructures, which are common in the United States of America (Manufactured Housing Research Alliance, 2002). Stacked block piers can be a single block pier or a double block pier (Figure 3). The pads can be a double pad or a triple pad and are installed under the main beams of prefabricated houses. The typical block pier or pad height ranges from $0.9 \mathrm{~m}$ to $2 \mathrm{~m}$ off the ground and spaced from $1.5 \mathrm{~m}$ to $3.0 \mathrm{~m}$ apart depending on the house design and soil type. The ground anchors are attached to the beams of prefabricated houses using steel straps to resist wind uplift forces. This footing system is adaptable to local site conditions and does not require a strict dimensional manufacturing and installation tolerance. Perimeter walls made up of stacked blocks may also be a part of a substructure. Reinforced block piers are also available supporting chassis where prefabricated houses are placed above (Federal Emergency Management Agency, 2009). This chassis is comprised of steel beams similar to the footing system of Moonen and Hermans (2013). The chassis beams are ideal since its light weight and can easily be assembled. The performance of the system for reactive soil has not been tested yet. This footing system has an advantage when installed on reactive soils since the contact between the substructure and ground is minimised. 
Block masonry piers or pads with ground anchor systems are constructed on a compacted or undisturbed ground. The installation of piers and ground anchor substructure is frequently completed in one to two working days. Though, the use of a pier and ground anchors, in most cases, is not considered as a stand-alone substructure for a single-detached dwelling. Addition of a perimeter encasement around the property is necessary acting as concrete wall support, forming a crawl space. Contrarily, the cost of crawl spaces is generally more expensive than slab systems and the construction period ranges from three to five working days (Manufactured Housing Research Alliance, 2002).

\section{Unconventional substructures}

Many on-ground substructures are derived from waffle rafts. For instance, a twoway post-tensioned waffle raft system was designed by Moldovan and Mathe (2016) to decrease the slab thickness and suffice ductility requirements. Other substructures derived from the typical waffle raft has EPS spanning across the entire floor area to provide passive insulation for houses. Marquez (2012) developed modular formwork, which are laid out on the ground and concrete is then poured. Likewise, a PE formwork similar to the shape of the EPS of waffle pods was developed to ease the placement of reinforcing bars, steel mesh and concrete (Kivi, 2013). A dome formwork (Figure 4), on the other hand, has a mould with cone support at the middle. Each dome inter-connects, providing a supplementary damp-proofing for capillary action with impervious liners. Additional reinforced beams or piles are used for sites with reactive soils (Kivi, 2013). The site preparation and construction period of these substructures are similar with that of waffle rafts.

Another novel substructure includes braced masonry piers or cast-in-place concrete pads with metal straps (Figure 5) that are utilised to resist vertical and lateral 
loads such as extreme wind conditions and earthquakes (Federal Emergency Management Agency, 2009). The metal straps are integrated in the footing system redistributing the loads to adjacent portions of the footing system. Though, if straps are loaded to their maximum capacity, redistribution of load may lead to progressive failure and collapse. To prevent progressive failure, redundant straps are necessary but may be inefficiently designed. These systems require typical ground improvement techniques such as ground compaction and application of gravel. The metal straps are installed and act as tie-downs to secure the house in place. The installation of these systems commonly takes approximately three to seven days, depending on the configuration of a proposed substructure.

Alternatively, a substructure comprised of a galvanised steel pan having a 3-bolt connected tubes (Figure 6) can be used. The V-shaped component has tubes connected with the pan by carriage bolts known as a beam clamp. The other ends of the tubes are then attached to the flanges of I-beams using connectors. The mechanism relates to the tension and compression load distribution from the base pad at one pier to the I-beams. This system can also be used for retrofitting existing substructures. This system is supplementing main substructures (e.g., block piers, pads and suspended beams) that can replace grounds anchors and metal straps. The installation generally takes around forty minutes to an hour per unit.

A hybrid substructure option is comprised of structural panels attached around the perimeter of houses with pour-in concrete (Figure 7). Concrete is cast into the structural panels that will act as a perimeter wall support. Block piers with beam supports are still necessary under the middle area of single-detached dwellings. Typical site preparation is required for installation, which includes grading and levelling. 
Installation time is affected by weather condition, site conditions and slopes. A typical construction of this substructure ranges from two to three days.

An alternative option is a substructure made up of several components including a pivoting deadman (Figure 8). It is applicable to most types of soil except gravelly sand grounds with little or no fines, since these soils does not have the cohesion the deadman mechanism requires. Houses are connected by a telescoping arm consisting of a locking frame clamp that transfers both tension and compression loads to the pivoting deadman. This system is a supplementary to other types of main substructures (e.g., block piers and pads) and the installation vary dramatically depending on the complexity of construction. The installation commonly takes around twenty minutes to an hour per unit.

Another substructure is made up of a permanent steel support column that replaces blocks and anchors of houses (Figure 9). It is designed to be fastened to I-beam flanges that has an adjustable cap plate that can be positioned to a desired elevation. In almost all cases, the installation time is faster than that of the conventional anchoring systems currently utilized. Under standard conditions with typical ground compaction as site preparation, installation should take no longer than one to two days for two people, with regards to setting of the anchors (Manufactured Housing Research Alliance, 2002). Once the installation is finished, the height cannot be adjusted since the rotation of the cap plate is restricted. The forces are transferred by the footing system to the cast-inplace concrete pad, typically the surface of an isolated or a strip footing. This system has the advantage of adjusting the slab in case of differential settlement due to soil swell and shrink, differential loading conditions, uneven ground conditions and earthquakes.

Micropile systems are emerging substructures for single-detached dwellings. These are solid pin substructures that are embedded into the ground without digging 
holes or pouring concrete (Figure 10). It is comprised of precast concrete or reticulated steel head installed on the ground surface, the steel bearing micropile are driven through the head using specialised hand-held tools. However, this substructure can only carry light structures such as decks, boardwalks, trails and pedestrian bridges. Further design analysis should be performed for housing application. It may also be challenging to drive into hard soil strata, which may cause initial deflection due to installation. Another variation of the micropile system uses multi-directional pin caps and piles, which provide support to the superstructure by resisting vertical loads including uplift, shear and moment loads. Minimal earthwork is necessary and can often be readily installed, nevertheless, these systems cost approximate twice as much as slab systems for the material cost. The installation of these micropile systems requires handheld drivers (e.g., 14-18 kg or petrol jackhammer for standard penetrable soil or impact drivers with proper hex and screw sizes). The installation is approximately fifteen minutes per group of micropiles. Typical suspended slabs can be poured or installed following standard construction process and time. Modular houses can be readily placed above the concrete or steel head.

An alternative substructure is an integrated wall-and-slab system, which also serves as a basement. The wall is constructed off-site using a high-strength, low-water concrete with no additional damp-proofing required while the slab is poured on-site with steel reinforcements and polypropylene fibres for a monolithic structure (Figure 11). Yu et al. (2008) also developed a similar footing system that is efficiently constructed in harsh climates. This footing system also reduces the depth of expansive soils prone to moisture changes by excavating the ground for a basement. Nevertheless, it is prone to lateral pore water pressure that necessitates the installation of drain pipes to reduce the moisture and stress experienced by the walls. The expected construction time for this 
precast system, including the assembly of basement walls, placing of steel and pouring of concrete for the substructure, capping with the main floor and soil back filling, is less than five days. This is significantly shorter than the typical cast-in-place construction of thirty-six days.

An integrated formwork for pier systems can also be used for houses. Permanent pier formwork was developed to easily pour concrete into the moulds and to control the quality of footings. Excavation is necessary depending on the depth of piers, and the standard construction period takes around three to five days depending on the chosen house design and site conditions. The form is installed with body snaps together with no additional specialised tools required but manual labour is needed for excavating the soil. Custom-fabricated vertical and horizontal rebars can also be placed using the rebar holder in- side the form (Figure 12). The integrated rebar holder reduces the amount of concrete needed and properly locates and holds rebars. Since this formwork only has one available dimension, there will be limited options that may cause an inefficient design.

\section{Advantages of prefabricated substructures}

The benefits of prefabricating substructures shall be recognised to know their feasibility to be prevalent in the future construction practices. The advantages of prefabricated systems depend on the building type and quantity for installation affecting the design viability, construction speed and substructure cost. Other benefits of prefabrication include better material quality control, fewer risks and a more sustainable construction method. This section provides the benefits of prefabricating substructures based on studies related to this topic and further discuss the potential substructures where prefabrication can be incorporated.

If the building type of the structure to be built is a low-rise lightweight and a large concrete volume is to be installed, prefabricated substructures will be a practical 
option. Prefabricated substructures will be more practical if implemented with low-rise lightweight structures such as prefabricated houses, this application is more technically feasible compared to tall and heavy buildings due to lower loads involved (Kumar, 1972). The quantity being installed also plays an important role to achieve significant savings (Wren, 2012). Prefabricated substructures in residential schemes is a more suitable alternative for large-scale construction since handling and transportation costs are important considerations, which are reduced when installed in large volumes (Huat and Mohammed, 2006). When dealing with a large-scale project, the lead time of substructure installation may be reduced since the components are efficiently procured and readily assembled on-site; this in turn allows onsite work to commence on the superstructure sooner (Wren, 2012).

With the use of prefabricated substructures, the construction period may be considerably reduced. The lead time for formwork installation, concrete curing and formwork decommissioning in constructing traditional cast-in-place residential substructures are eliminated (Moonen and Hermans, 2013; Yu et al., 2008). The delays due to inclement weather will also be prevented through effective planning and efficient procurement (Kumar, 1972). In addition, the delays due to different material delivery schedules are not experienced since the components of prefabricated substructures are delivered altogether and the only on-site process needing to take place is assembly. Furthermore, reduction of the construction period also reduces the disturbance of the construction work on the surrounding environment and decreases unexpected expenses (Escrig Pérez, 2010).

The price of prefabrication is easier to control since it is fixed and has lesser unexpected costs (Escrig Pérez, 2010). Furthermore, if prefabricated substructures are 
industrialised, substantial savings can further decrease the direct cost due to large-scale production without compromising their quality (Kumar, 1972).

Prefabrication usually lead to a quality-controlled construction. The materials being used are commonly of better quality, the staff are well-trained and specialised, and the quality of prefabricated products and processes are consistently supervised and checked (Venables and Courtney, 2004). The manufacturing process has lesser possibilities for human error compared to in-situ construction. Thus, the quality of prefabricated products offers lesser uncertainty in assembly and footing price due to fewer incidents and more durable prefabricated components (Escrig Pérez, 2010).

Prefabricated substructure construction will provide better working conditions reducing accident risks and more stable environment (Pujadas Gispert, 2016). There are also fewer subcontractors involved that simplifies management, conflicts and delays (Escrig Pérez, 2010). The scope of work is more consistent in prefabrication and assembly unlike in conventional construction where there are seasonal fluctuations in labour depending on the stage of the construction (Kumar, 1972).

Prefabricated substructure systems may avoid over-dimensioning and promote reusing and recycling, leading to a more sustainable option. Most prefabricated components applied value engineering to reduce material wastage preventing overdimensioning, which reduces the amount of resources and energy used (Pujadas Gispert, 2016). Furthermore, most prefabricated systems are manufactured based on optimised design and production, which reduces carbon emissionsto the atmosphere (Wren, 2012). Most prefabricated systems might also be dismantled instead of demolishing the whole footing due to its modular design, encouraging the reuse and recycle of the modules (Pujadas Gispert, 2016). Some prefabricated substructures may also be constructed using recycled materials and some parts such as void formers can be reused, which 
reduces the carbon footprint, cost and resource requirements of the systems (Moonen, 2014; Moonen and Hermans, 2013).

\section{Challenges in the prefabrication of substructures}

To develop an ideal prefabricated substructure design, considerations of requirements for structural design, manufacturing design, handling and transportation of goods, assembly process and system sustainability are important. These considerations affect the integrity of the footing system, total cost and construction lead time (Monash University, 2017). These factors considered in designing an ideal prefabricated substructure system are discussed in this section.

\section{Structural design requirements}

An ideal design of a prefabricated substructure should have a mechanism to adapt with different site classifications (Table 1, AS 2870-2011), specifically sites with moderate to highly reactive soils. These soils have high potential to change their volume depending on the presence and characteristics of clay particles and soil moisture, shrinking with soil moisture decrease and swelling with soil moisture increase (Teodosio et al., 2019). The interaction between soils and footing systems is affected by weather factors (i.e. soil suction change), soil factors (i.e. soil modulus, shrink-swell index, hydraulic conductivity), the depth where ground movement extends (Briaud et al., 2016) and loading factors (Standards Australia, 2012, 2012, 2002). Methods to prevent substantial amount of damage (Gad, 2016), not only to substructures but also for superstructure elements of houses (i.e. walls, ceilings, frames, slabs designed base on Standards Australia, 1998, 2009, 2011b), are either (1) to stiffen substructures or (2) to isolate superstructures. Stiffening of shallow or slab-on-ground substructures are implemented to resist soil movement (Far and Flint, 2017), which is commonly 
effective for stable to highly reactive sites. Isolation of the superstructure is achieved by installing a system with minimum contact area between footings and founding ground. These substructure systems are comprised of piers and pads acting as stumps for isolation. The ideal structural design of a prefabricated substructure is aptly developing a system with structural integrity yet economical. From the review of different substructure systems, slab systems (e.g., waffle and stiffened rafts) are commonly used for reactive soils in Australia for practicality and easier construction (Far and Flint, 2017; Standards Australia, 2011a). Slab substructures are more advantageous than deep substructures (e.g., piles an piers) when sites have deep presence of reactive soils, which will make costs of deep substructures costly.

Another structural challenge in prefabricating substructures is the development of robust connections that will transfer forces and moments and will make the global structure act uniformly. Since prefabricated substructures will be constructed on-site by assembling the delivered parts from a factory. To obtain an effective assembly, the connection between the substructure-to-substructure and the substructure-tosuperstructure should have a monolithic behaviour. Connections and joints are the most critical part specifically when the structure is subjected to dynamic loads, which may limit the use of prefabricated footings in areas prone to ground movements and cyclic soil swelling and shrinking (Marquez, 2012).

Design challenges such as specificity and coordination might be some issues considered in developing modular and panelised prefabricated substructures. These systems are typically designed depending on the configuration of the superstructure of the house. Substructure designs are often made specifically for unique combinations of loads and type of soils, which may be challenging to create a modular and panel designs that will be applicable to most situations (Marquez, 2012). Furthermore, dimensional 
variety is inevitable due to the differences of the magnitude of loads along the structural spans.

\section{Manufacturing requirements}

Balancing the structural integrity and cost of a system is challenging to achieve to develop an ideal prefabricated solution. A possible key to achieve this goal is to apply optimised manufacturing, a systematic method to minimise material usage and waste disposal (Dilanthi, 2015). Optimised manufacturing does not only reduce the cost through material and waste reduction, this also enhances the end product and process efficiencies (Monash University, 2017; Standards Australia, 2016). To maximise the benefit given by an optimised prefabricated substructure, it is important that the manufacturing processes are considered thoroughly from the design outset. Based on past studies, it is well proven that the optimised philosophy enable successful results with design, manufacturing and assembly considerations (McFarlane and Stehle, 2014). The philosophy of thinking optimisation permits manufacturing in controlled factory conditions, leading to a more efficient and safe construction of prefabricated footings assembled on-site (Yu et al., 2013).

Another important consideration for an ideal prefabricated solution is using dimensional coordination. Dimensional coordination is a manufacturing tool to organise different elements independently to be connected and integrated as a whole (American Society for Testing and Materials, 2002; Bergvall, 1977). This method does not only improve the assembly of a structure considering strict tolerance, this also improves the flexibility of material usage and practicality of design (Adams and Bradley, 1945). Modular or panelised coordination is defined as the definitive goal of dimensional coordination, which will help to industrialise substructures through prefabrication 
(Leung, 1971). Modular or panelised coordination, together with optimised manufacturing, permits advantageous usage of materials, hence, reducing material and total cost. In the dimensional coordination, services for electricity and plumbing must be considered. The holes for the services (i.e., wiring and plumbing) can be preformed during the manufacturing process through top beams as applied by Yu et al. (2008).

If the dimensions of prefabricated substructures are modularised, most system dimensions may be overdesigned (Pujadas Gispert, 2016). The design of modular and panelised substructure systems shall be conducive for procurement. Prefabricated substructures shall be handled carefully and delivered in a pristine condition. However, prefabricated substructures are bulky and heavy. Hence, it is advisable that it has a stackable design to optimise the space in a factory and a delivery truck. In addition, the transportation is costly, and the economical delivery radius is around $200 \mathrm{~km}$ from the factory (Yu et al., 2008).

\section{Handling and transportation requirements}

An ideal prefabricated substructure shall be safe and easy to handle (Australian Government, 2011; Victorian Legislation, 2007, 2004) and to transport (Brassington, 2012; Commonwealth, 2011, 1995). Handling and transportation are areas in particular where prefabricated solutions introduce novel considerations (Beck, 1999). These considerations include lifting of prefabricated elements (Standards Australia, 1986), packaging (Australasian Procurement and Construction Council, 2014), transportation load restraints (National Transport Commission et al., 2004), safe containers (International Maritime Organization, 2013) and proper documentation. The constraint in transportation due to the vehicle size may also limit the dimension of prefabricated footing systems. Furthermore, weight restrictions and site access for cranes should be taken into account (Monash University, 2017). 


\section{Assembly requirements}

The main challenges of a prefabricated solution are: (1) to have a rapid installation on-site without any labour-intensive process and (2) to have proper tolerance for ease of installation. On-site rapid installation of prefabricated solutions should comply with safety work guidelines (SafeWork Australia, 2012; WorkSafe Victoria, 2017, 2008), neglect non-essential earthwork (e.g. levelling) (Cement and Concrete Association of Australia, 2003) and disregard unnecessary temporary structures (e.g. formwork) (Australian Building Codes Board, 2015). Although labour is much less intensive for prefabricated substructures, specialised skills for assembly are required (Vokes and Brennan, 2014). For ease of installation during the assembly stage, tolerance should be well-considered in the design outset and manufacturing (Face et al., 2002). Superstructures shall be positioned ensuring that the alignment of actual connection locations of substructures are within acceptable tolerance (American Concrete Institute, 2002). The assembly of connections using joints shall also have a strict tolerance and must fit aptly with the elements being connected (Jaspart and Weynand, 2016a, 2016b). Furthermore, it is advisable for an ideal prefabricated substructure to be reused without compromising the structural integrity of an entire residential structure (Department of Sustainability, Environment, Water, Population and Communities, 2012).

\section{Conclusion}

The consistently strong Australian economy and stable population growth have led to a higher demand for residential structures. The full potential of prefabricated construction cannot be achieved without addressing opportunities to prefabricate the substructure. Prefabrication of substructures for single-detached dwellings has the potential to significantly improve construction quality, construction time and 
sustainability. This may also reduce construction delays, labour shortages and unexpected expenses. Thus, this paper presented the existing conventional and unconventional substructures available for residentials and reviewed the advantages and challenges of constructing and industrialising innovative prefabricated substructures.

The main benefit of prefabricating substructure systems is to reduce construction time, which commonly extends to more than five days for conventional substructures. To develop a structurally robust and economical system, challenges in structural design, manufacturing, handling and transport, and assembly requirements are ought to be considered. To achieve the full potential of a developed prefabricated substructure, innovative methods such as topology optimisation can be applied in the design process. Furthermore, connections may be a weakness for prefabricated structures since this creates lack of monolithic global substructure actions, nonetheless, articulated joints in the slab can be added to lessen the effect of restraints and eventually reducing damage due to the cyclic shrink-swell movements of reactive soils.

Prefabrication of substructures have significant advantages in the construction of residential structures but there are issues that need thorough investigations. Moreover, prefabrication of substructures may have more challenges than that of superstructure components since thorough considerations of both structural and soil behaviour are necessary. Further study of the potential of prefabricating substructures is necessary because its application is not limited to commercial construction but also for other constructions requiring rapid substructure installations such as houses for areas affected by disasters and refugee camps. 


\section{Acknowledgements}

The authors would like to thank the Australian Research Council - Centre for Advanced Manufacturing of Prefabricated Housing (ARC-CAMPH) Project ID IC150100030.

\section{References}

Adams, M.W., and P. Bradley†. 1945. Dimensional Coordination *. Journal of the American Ceramic Society 28, no. 8 (August 1): 217-226.

American Concrete Institute. 2002. 117-06 Specifications for Tolerances for Concrete Construction and Materials: 70.

American Society for Testing and Materials. 2002. Standard Guide for Dimensional Coordination of Rectilinear Building Parts and Sysems.

Anchorpanel. Accessed July 16, 2018. http://www.anchorpanel.com/.

Anchor Systems. Accessed June 12, 2018.

https://www.anchorsystems.co.uk/products/anchor-post/.

Australasian Procurement and Construction Council. 2014. Procurement of Construction Products - a Guide to Achieving Compliance.

Australian Building Codes Board. 2015. Temporary Structures Standard.

Australian Bureau of Statistics. 2017. Australian Bureau of Statistics: Building Approvals. http://www.abs.gov.au/Ausstats/abs@.nsf/mf/8731.0.

Australian Government. 2011. Work Health and Safety Act 2011.

Barlow, J., and R. Ozaki. 2005. Building Mass Customised Housing through Innovation in the Production System: Lessons from Japan. Environment and Planning A 37, no. 1: 9-20.

Beck, W.G. 1999. Prefabricated Modular Concrete Foundation Wall Systems and Methods of Constructing Prefabricated Modular Concrete Foundation Wall Systems. http://www.google.com/patents/US5953864.

Bergan, P.O. 1972. System of Domes for Use in Molding Concrete Slabs. https://patents.google.com/patent/US3638902A/en?oq=US3638902A.

Bergvall, L. 1977. Dimensional Coordination as a Tool for Industrialisation. In Metric Dimensional Coordination - The Issue and Precedent.

Brassington, B. 2012. Code of Practice for Packing of Cargo Transport Units. 
Briaud, J.-L., R. Abdelmalak, X. Zhang, and C. Magbo. 2016. Stiffened Slab-on-Grade on Shrink-Swell Soil: New Design Method. Journal of Geotechnical and Geoenvironmental Engineering 142, no. 7: 04016017.

Butler Jr, R.P. 2000. Prefabricated Concrete Footings. http://www.google.com/patents/US6141936.

Cameron, D., Walsh, P., Richards, B. 1987. In $9^{\text {th }}$ Regional Conference for Africa on Soil Mechanics and Foundation Engineering, 977-989.

Cannington, D. 2017. Australian Property: Australian Housing Chartbook.

Cement and Concrete Association of Australia. 2003. Guide to Residential Floors. St Leonards, NSW: Cement and Concrete Association of Australia.

Commonwealth Securities Limited. 2017. Economic Insights, Australia home size hits 20-year low: CommSec Home Size Trends Report.

Daley, J., B. Coates, T. Wiltshire, and Grattan Institute. 2018. Housing Affordability: Re-Imagining the Australian Dream. Carlton: Grattan Institute. https://grattan.edu.au/report/housing-affordability-re-imagining-the-australiandream.

Department of Sustainability, Environment, Water, Population and Communities. 2012. Construction and Demolition Waste Guide - Recycling and Reuse across the Supply Chain.

Department of the Army USA. 1983. Technical Manual TM 5-818-7, Foundations in Expansive Soils.

Diamond Piers. Accessed May 23, 2018. https://www.diamondpiers.com/.

Dilanthi, M.G.S. 2015. Conceptual Evolution of Lean Manufacturing.

Downer, M.J., and R.W. Tanner. 2008. Rain Water Recycling System Using the Void Spaces of Pods Forming a Waffle Slab. https://patents.google.com/patent/WO2008070928A1/en?oq=WO2008070928A 1.

Escrig Pérez, C. 2010. Evolución de Los Sistemas de Construcción Industrializados a Base de Elementos Prefabricados de Hormigón. https://upcommons.upc.edu/handle/2117/8398.

Face, S.A., T.C. Heist, R.A. Kaden, R. Martin, P. Meza, A. Morcos, C.B. Morgan, et al. 2002. 117-90 Standard Specifications for Tolerances for Concrete Construction and Materials: 12. 
Far, H., and D. Flint. 2017. Significance of Using Isolated Footing Technique for Residential Construction on Expansive Soils. Frontiers of Structural and Civil Engineering 11, no. 1: 123-129.

Federal Emergency Management Agency. 2009. Protecting Manufactured Homes from Floods and Other Hazards. https://www.fema.gov/media-librarydata/20130726-1502-20490-8377/fema_p85.pdf.

Firth Industries. 2013. Firth RibRaft TC3 Concrete Slab Floor. https://www.youtube.com/watch?v=ga5gS2BgFGM.

Friedman, A. 1992. Prefabrication versus Conventional Construction in Single-family Wood-frame Housing: Costs of Conventional and Prefabricated Canadian Homes Compared in a Survey of 15 Manufacturers in the Provinces of Quebec and Ontario. Building Research \& Information 20, no. 4 (July): 226-228.

Gad, E. 2016. A Slab of Confusion. Building Connection.

Gerszewski, M. 1990. Precast Concrete Foundation Elements and System and Method of Using Same. http://www.google.com/patents/US4918891.

Gibb, A.G. 1999. Off-Site Fabrication: Prefabrication, Pre-Assembly and Modularisation. John Wiley \& Sons.

Gilpin, D.C., B.D. Stiles, and S.R. Stiles. 2017. Concrete Void Forming Method and Device. https://patents.google.com/patent/US20170275903A1/en?oq=US+20170275903 $+\mathrm{A} 1$.

Gispert, E. 2016. Prefabricated Foundtions for Housing Applied to Room Modules. https://upcommons.upc.edu/handle/2117/96274.

Golledge, B.F., M.A. GOLLEDGE, and L.A. GOLLEDGE. 2014. Slab Construction. https://patents.google.com/patent/WO2014165913A1/en?oq=WO2014165913A 1.

Gonsalves, M. 1996. Concrete Slab Foundation and Method of Construction. https://patents.google.com/patent/US5540524A/en?oq=US5540524A.

Gordon, M.B. 2007. Storage of Water, Rainwater or Grey Water or Other Liquids beneath a Concrete Floor Slab. https://patents.google.com/patent/WO2007016721A1/en?oq=WO2007016721A 1.

Higuchi, T. 1979. Method for Forming a Continuous Footing with Prefabricated Footing Blocks. http://www.google.com/patents/US4163621. 
Homer, H.D. 1965. Retaining Wall and Section Thereof.

Huat, B.B., and T.A. Mohammed. 2006. Finite Element Study Using FE Code (PLAXIS) on the Geotechnical Behavior of Shell Footings. Journal of Computer Science 2, no. 1: 104-108.

InnoTecTrading. 2010. Krinner Ground Screws - THE Foundation System for Solar Projects. https://www.youtube.com/watch?v=EWGeX4Ip7nU.

Inoue, K., H. Inokuchi, T. Ueda, and T. Doi. 2005. Plane Lattice Hollow Concrete Slab and Cross Arm Brace. https://patents.google.com/patent/US20050138877A1/en?oq=US20050138877A 1.

International Maritime Organization. 2013. Revised Recommendations on Harmonized Interpretation and Implementation of the Iternational Convention for Safe Containers (CSC).

Jaillon, L., and C.S. Poon. 2009. The Evolution of Prefabricated Residential Building Systems in Hong Kong: A Review of the Public and the Private Sector. Automation in Construction 18, no. 3: 239-248.

Jaspart, J.-P., and K. Weynand. 2016a. Design of Joints i Steel and Composite Structures.

Jeff Gutterud. 2011. Pin Foundations Diamond Pier Overview As Seen on Public Television's Hometime. https://www.youtube.com/watch?v=0dXqDaVj3mQ.

Jones, L., Jefferson, I. 2012. Expansive Soils, ICE Manual of Geotechnical Engineering. ICE Publishing, London, 413-441.

Jr, D.P.G. 1999. Insulated Concrete Slab Assembly. https://patents.google.com/patent/US5934036A/en?oq=US5934036A.

Kivi, A.K. 2013. Evaluation of Structural Dome Formwork Systems in Concrete Pavement Applications. University of Waterloo. https://uwspace.uwaterloo.ca/handle/10012/7993.

Koukourou, P. S., P.M. Bayetto, and others. 1987. The Waffle Pod Footing System. In Fourth National Local Government Engineering Conference 1987; Preprints of Papers, 117. Institution of Engineers, Australia. https://search.informit.com.au/documentSummary;dn=527830105226176;res=I ELENG.

Koukourou, Peter S. 1988. Building Foundation. https://patents.google.com/patent/US4788809A/en?oq=US4788809A. 
Kumar, V.K. 1972. Industrialized Foundations for Low-Rise Light-Weight Buildings. Virginia Polytechnic Institute and State University.

Lassen, J. o slashed rgen. 1998. Element for Use in Making a Reinforced Concrete Structure with Cavities, Filler Body for Making Such an Element, and Method of Making a Reinforced Concrete Structure with Cavities. https://patents.google.com/patent/US5797230A/en?oq=US5797230A.

Leonardis, N. 1989. Foundation Form Work. https://patents.google.com/patent/US4831803A/en?oq=US4831803A.

Leung, Y. 1971. Dimensional Coordination of Industrialized Metal Buildings. Thesis. https://scholarship.rice.edu/handle/1911/89233.

Lewis, K. 2017. HIA Trades Report September 2017 Quarter: 6.

Li, J., Cameron, D.A. 2002. Case Study of Courtyard House Damaged by Expansive Soils. In Journal of Performance of Constructed Facilities, 16:169-175.

Lichtenberg, J. 2006. Slimbouwen, a Strategy for Efficient and Sustainable Building Innovation. In Proceedings Joint.

Lindsay, R.L. 2006. Under Slab Water Storage. https://patents.google.com/patent/WO2006032090A1/en?oq=WO2006032090A 1.

Llorens Duran, J.I. de, and E. Pujadas Gispert. 2015. Lightweight Recoverable Foundations on Suitable Ground. In World Sustainable Building 2014 Barcelona Conference, 1-7. Green Building Council España. https://upcommons.upc.edu/handle/2117/85209.

Macchi, A.J. 1965. Concrete Floor and Ceiling Slab Construction. https://patents.google.com/patent/US3213581A/en?oq=US3213581A.

Major, P.W., and A.T. Peake. 2003. Foundations. https://patents.google.com/patent/EP1335073A2/en?oq=EP1335073A2.

Manufactured Housing Research Alliance. 2002. Guide to Foundation and Support Systems for Manufactured Homes.

Marquart, C.M. 1987. Prefabricated Home Foundation Skirt System. http://www.google.com/patents/US4656797.

Marquez, A. 2012. Componente Modular Prefabricado de Concreto Para Placa Defundacion Superficial Reticular Alveolada. Tecnologia y Construccion 22, no. 2: $23-33$. 
McFarlane, A., and J. Stehle. 2014. DfMA: Engineering the Future. In Proceedings of Council on Tall Buildings and Urban Habitat (CTBUH) 2014 Shanghai Conference, 16:508-516.

Mehdizadeh, A., M.M. Disfani, R. Evans, E. Gad, A. Escobar, and W. Jennings. 2017. Static Load Testing of Concrete Free Reticulated Micropiles System. In . Accessed September 15. https://www.researchgate.net/profile/A_Mehdizadeh/publication/307905816_Sta tic_Load_Testing_of_Concrete_Free_Reticulated_Micropiles_System/links/57d 13bff08ae5f03b48a731f/Static-Load-Testing-of-Concrete-Free-ReticulatedMicropiles-System.pdf.

Menegon, S., J.L. Wilson, S. Hughes, and E. Gad. 2018. The development of two new innovative precast building core connections. In Australasian Structural Engineering Conference 2018, 506-516.

Miao, L., Wang, F., Cui, Y., Shi, S. 2012. Hydraulic Characteristics, Strength of Cyclic Wetting-Drying and Constitutive Model of Expansive Soils, In $4^{\text {th }}$ International Conference on Problematic Soils, 303-322.

Miller, F.R., and S.G.P. Blundell. 2016. Concrete Flooring. https://patents.google.com/patent/US9359760B2/en?oq=US9359760B2.

Millman, P. 1987. Bubble Relief Form for Concrete. https://patents.google.com/patent/US4702048A/en?oq=US4702048.

Moldovan, I., and A. Mathe. 2016. A Study on a Two-Way Post-Tensioned Concrete Waffle Slab. Procedia Technology 22: 227-234.

Monash University. 2017. Handbook for the Design of Modular Structures.

Moonen, S.P.G. 2014. Rapidly Building with Lightweight Modules and a Dry Assembled Foundation: Used in a Mock-up for Home Units Made out of Reclaimed Materials. In , 209-221. http://library.witpress.com/viewpaper.asp?pcode=MAR14-017-1.

Moonen, S.P.G., and K. Hermans. 2013. Building with Materials from Demolition Projects. In Proceedings of the 11th International Detail Design in Architecture (DDiA) Conference, 21:22. https://pure.tue.nl/ws/files/3973436/601592669214321.pdf.

National Transport Commission, National Transport Commission, and Roads and Traffic Authority of New South Wales. 2004. Load Restraint Guide: Guidelines 
and Performance Standards for the Safe Carriage of Loads on Road Vehicles. Melbourne: National Transport Commission.

Nelson, S. 2008. Modular Housing: Prefab and Proudly Upmarket. Building Connectionno. Summer Quarter 2008: 24.

O’Grady, J., G. Italiano, D. Fry, R. Boykett, P. Darbyshire, and C. Ryan. 2008. Cavity Former. https://patents.google.com/patent/US20080035830A1/en?oq=US20080035830A 1.

O’Grady, J.F., G. Italiano, D.A. Fry, R.K. Boykett, P. Darbyshire, C.T. Ryan, and The Australian Steel Company. 2005. Cavity Former. https://patents.google.com/patent/WO2005108701A1/en?oq=W+O+2005\%2f10 $8701+\mathrm{Al}$.

Oliver Technologies Inc. Accessed September 8, 2018. https://olivertechnologies.com/products/foundation-stabilizing-systems/.

Ong, R., T. Dalton, N. Gurran, C. Phelps, S. Rowley, G. Wood, and AHURI LTD. 2017. Housing Supply Responsiveness in Australia: Distribution, Drivers and Institutional Settings. AHURI Final Report. Australian Housing and Urban Research Institute Limited. http://www.ahuri.edu.au/research/final-reports/281.

Peer, C.V. de. 1995. Foundation Construction. https://patents.google.com/patent/US5421136A/en?oq=US5421136A.

Pontarolo, V. 2000. Modular Element for the Support and Ventilation of Floors. https://patents.google.com/patent/EP0803618B1/en?oq=EP0803618B1.

Rauenhorst, G.A. 1979. Hollow-Core Concrete Slabs and the Method of Making the Same. https://patents.google.com/patent/US4141946A/en?oq=US4141946A.

RMIT. 2018. Features of Waffle Raft Slabs. Accessed May 18. https://emedia.rmit.edu.au/dlsweb/Toolbox/buildright/content/bcgbc4010a/09_fo oting_systems/06_concrete_slabs/page_006.htm.

SafeWork Australia. 2012. Safe Design of Structures: Code of Practice. Safe Work Australia.

ScrewFastFoundations. 2010. ScrewFast Foundations Innovative GRIP® Pile Foundation. https://www.youtube.com/watch?v=Jp5gdg3g_d4.

Sebastian, R. 2010. Low Disturbance Urban Projects through Smart Manufacturing and BIM. ResearchGate. 
https://www.researchgate.net/publication/236208837_Low_Disturbance_Urban_ Projects_through_Smart_Manufacturing_and_BIM.

Sebastian, R., C. Claeson-Jonsson, and R. Di Giulio. 2013. Performance-Based Procurement for Low-Disturbance Bridge Construction Projects. Construction Innovation 13, no. 4: 394-409.

Skinner, H., Crilly, M., Charles, J. 1998. Numerical Models for the Design of Shallow Foundations for Low-rise Buildings, In Application of Numerical Methods to Geotechnical Problems, 655-664.

Smorgon, A.-T., and D. Manual. 1999. Your Guide to Faster Floors Hume Slab.

Song, J., W.R. Fagerlund, C.T. Haas, C.B. Tatum, and J.A. Vanegas. 2005. Considering Prework on Industrial Projects. Journal of Construction Engineering and Management 131, no. 6: 723-733.

Standards Australia. 1986. AS 1418.1 1986: Cranes, Hoists and Winches - Part 1 General Requirements. Sydney: Standards Australia.

Standards Australia. 2011. AS 2870-2011: Residential slabs and footings. Australian Standard.

Stapledon, N. 2010. A History of Housing Prices in Australia 1880-2010. https://papers.ssrn.com/sol3/papers.cfm?abstract_id=1711224.

Steven Winter Associates. 2006. Research and Analysis for Manufactured Housing Foundations.

Sun, X., J. Li, and G. Ren. 2017. Residential Footing Design on Expansive Soils: A Review of Australian Practice. Electronic Journal of Geotechnical Engineering 22, no. 10: 3939-3964.

Surefoot. Accessed May 23, 2018. https://surefootfootings.com.au/.

Swinimer, K. 2005. Footing Form. http://www.google.com/patents/US6840491.

Teodosio, B., K.S.K. Baduge, P. Mendis and D. Heath. 2018. Soil-structure interaction design methods for residential structures on reactive soils. In Australian Structural Engineering Conference (ASEC), 49:58.

Teodosio, B., K.S.K. Baduge and P. Mendis. 2019. An optimized prefabricated raft footing system for houses on shrink-swell soils: preliminary results. In Modular Offsite Construction (MOC) Summit.

The Australian Steel Company. 2005. Cavity Former. https://patents.google.com/patent/WO2005061804A1/de.

Tie Down Engineering. Accessed July 18, 2018. http://www.tiedown.com/. 
Van Elle. 2017. Smartfoot Brochure.Pdf. Accessed September 15. https://www.vanelle.co.uk/Downloads/Smartfoot\%20Brochure.pdf.

Venables, T., and R. Courtney. 2004. Modern Methods of Construction in Germany. UK: Pera Innovation Limited.(Department of Trade and Industry (DTI)) Capítulo 6: 2860-2871.

Victorian Legislation. 1993. Building Act 1993.

VicRoads. Accessed May 30, 2019. https://www.vicroads.vic.gov.au/business-andindustry/heavy-vehicle-industry/heavy-vehicle-road-safety/transporting-housesand-prefabricated-buildings.

Vokes, C., and J. Brennan. 2014. Technology and Skills in the Construction Industry: Evidence Report 74.

Vroom. 2017. Pre-Fab Foundation Beams - Vroom Foundation Technology. http://www.vroom.nl/en/products/5-pre-fab-foundation-beams.

Wells, D. 2003. Footing Form. http://www.google.com/patents/US6543742.

WIPO. 2017a. Prefab in History. PrefabAUS. Accessed September 8. http://www.prefabaus.org.au/prefab-in-history/.

WorkSafe Victoria. 2008. Working Safely in the General Construction Industry - a Handbook for the Construction Regulations.

WP Fail Safe Footer. Accessed July 15, 2018. https://failsafepierfooter.com/.

Wren, C. 2012. Chapter 91 Modular Foundations and Retaining Walls. In ICE Manual of Geotechnical Engineering, 1343-1350. Thomas Telford Ltd.

Yu, H., M. Al-Hussein, S. Al-Jibouri, and A. Telyas. 2013. Lean Transformation in a Modular Building Company: A Case for Implementation. Journal of Management in Engineering 29, no. 1 (January): 103-111.

Yu, H., M. Al-Hussein, R. Nasseri, and R.J. Cheng. 2008. Sustainable Precast Concrete Foundation System for Residential Construction. Canadian Journal of Civil Engineering 35, no. 2: 190-199. 
Table 1. Site classification based on surface characteristic movement (ys) (Standards Australia 2011).

\begin{tabular}{ccc}
\hline Site class & Foundation & $\mathrm{y}_{\mathrm{S}}(\mathrm{mm})$ \\
\hline $\mathrm{A}$ & rock and sand & 0 \\
$\mathrm{~S}$ & slightly reactive silt and clay & $0-20$ \\
$\mathrm{M}$ & moderately reactive silt and clay & $20-40$ \\
$\mathrm{H} 1$ & highly reactive clay & $40-60$ \\
$\mathrm{H} 2$ & very highly reactive clay & $60-75$ \\
$\mathrm{E}$ & filled, soft silt or clay, loose sands, sandslip, mine subsidence, collapsing & $>75$ \\
$\mathrm{P}$ & & varying \\
\hline
\end{tabular}

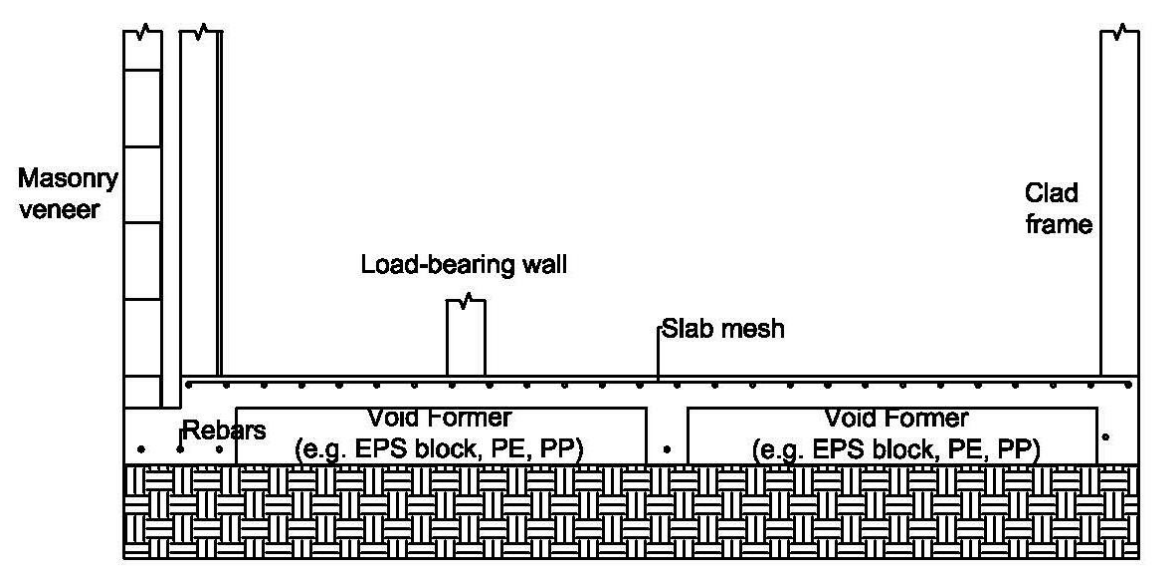

Figure 1. A typical waffle pod system adapted from AS 2870-2011 (Adapted from

Standards Australia, 2011a).

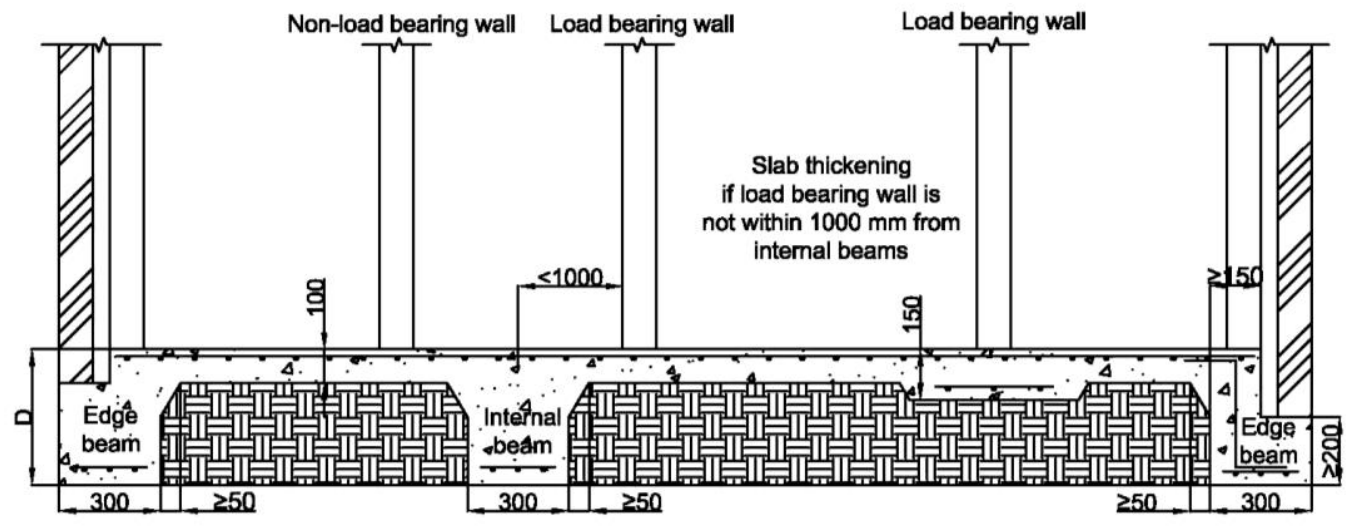

Figure 2. A typical stiffened raft design adapted from (Adapted from Standards Australia, 2011a). 

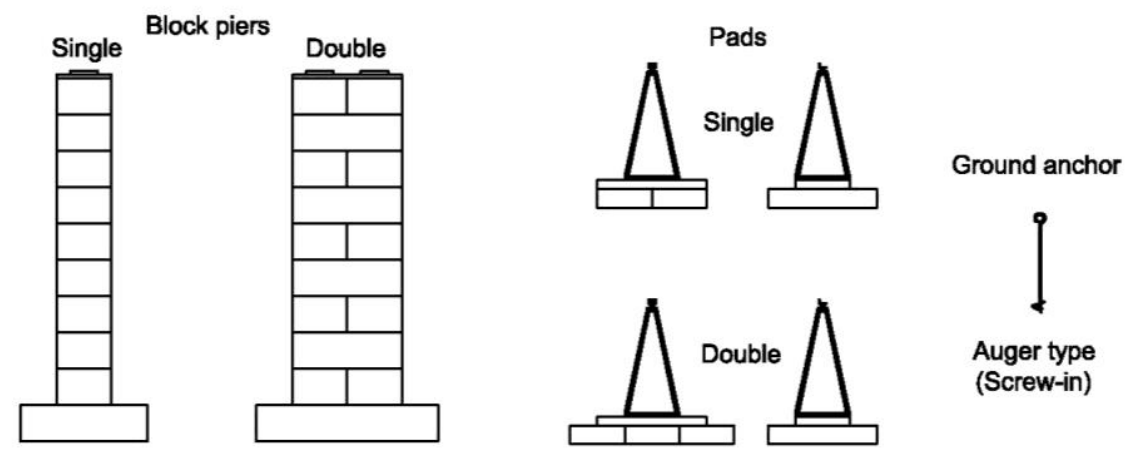

Figure 3. Footing systems using single or double block piers or pads with ground anchors (Adapted from Manufactured Housing Research Alliance, 2002).
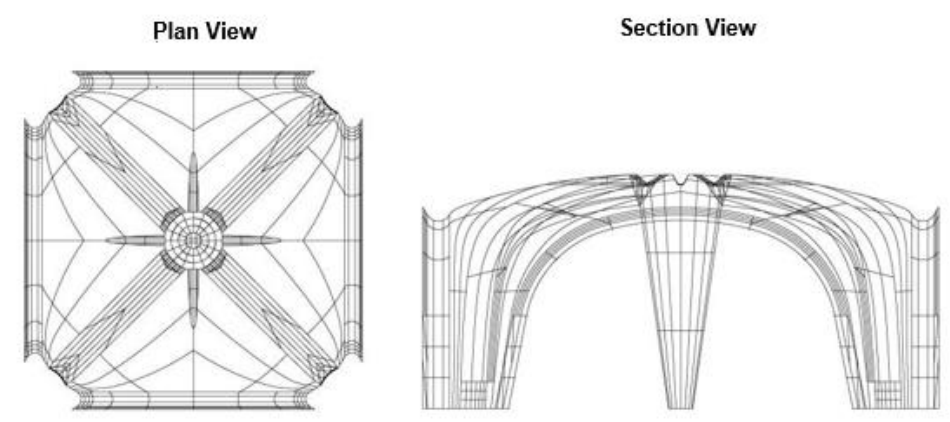

Figure 4. An on-ground permanent dome formwork footing system (Adapted from Kivi, 2013).

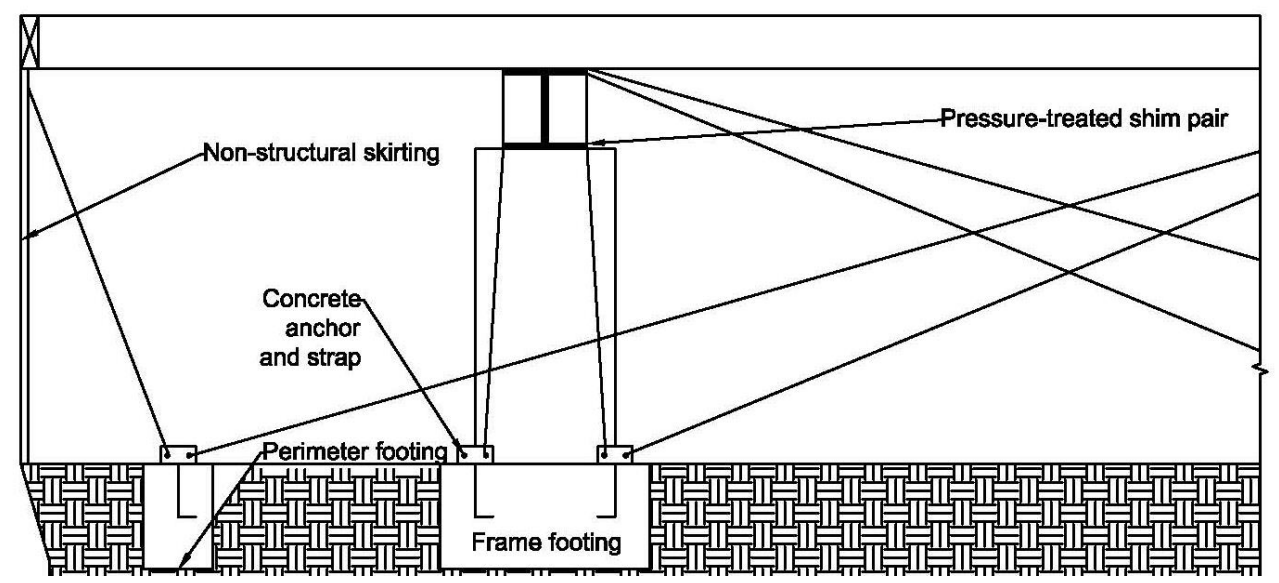

Figure 5. A footing system with bracing using metal straps (Adapted from Federal Emergency Management Agency, 2009).. 

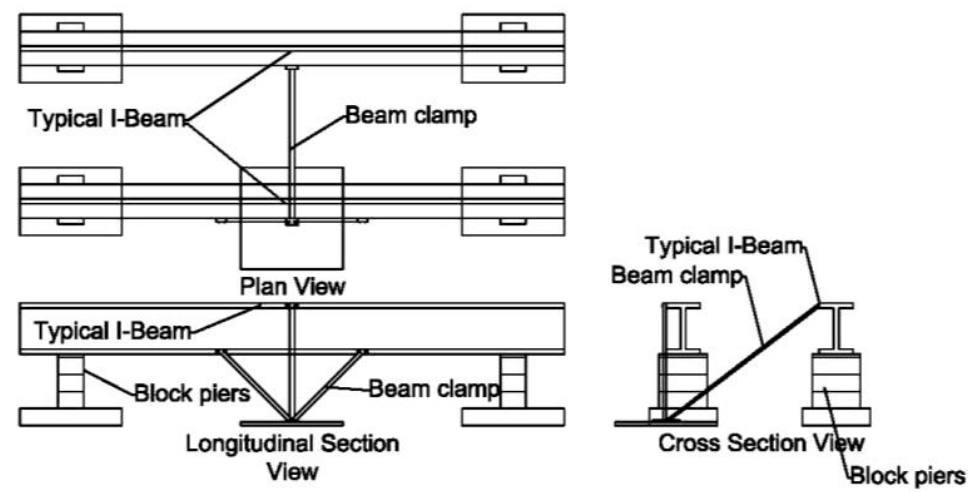

Figure 6. A footing system with an I-beam and a beam clamp (Adapted from Oliver Technologies Inc. and Tie Down Engineering).

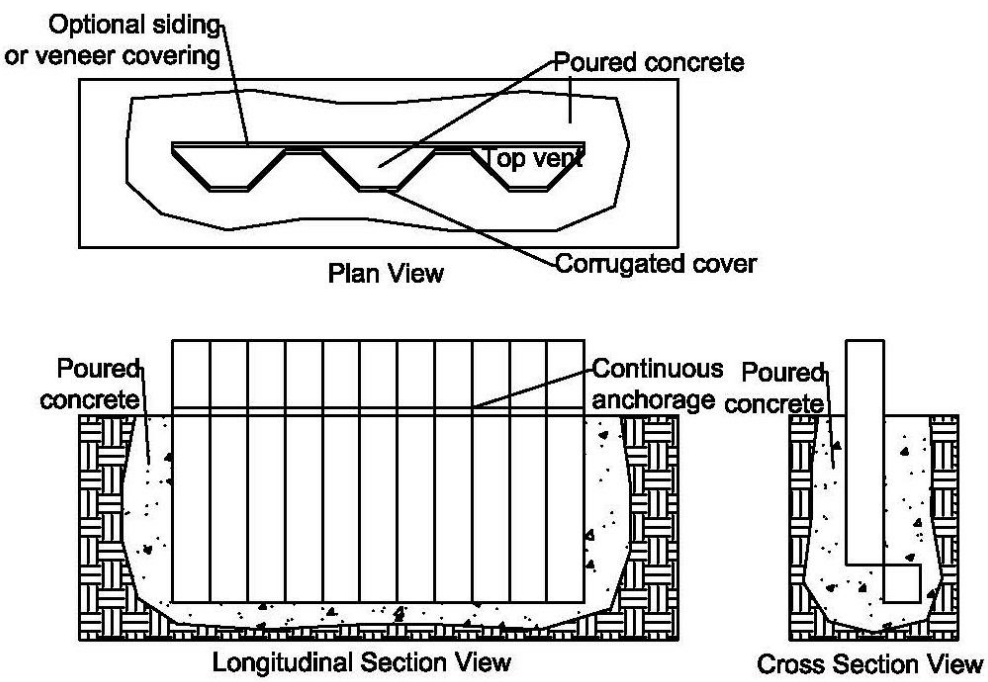

Figure 7. A footing system with structural panels and cast-in-place concrete (Adapted from Anchorpanel®). 


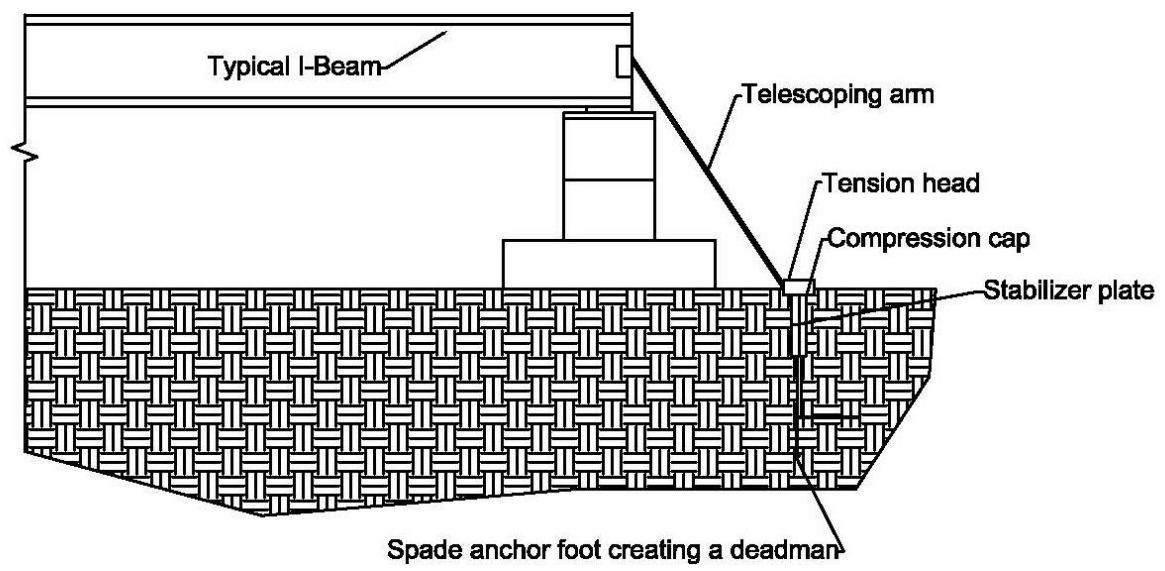

Figure 8. A footing system with telescoping arm and a spade anchor deadman (Adapted from JM Products, Inc. and Steven Winter Associates, 2006).

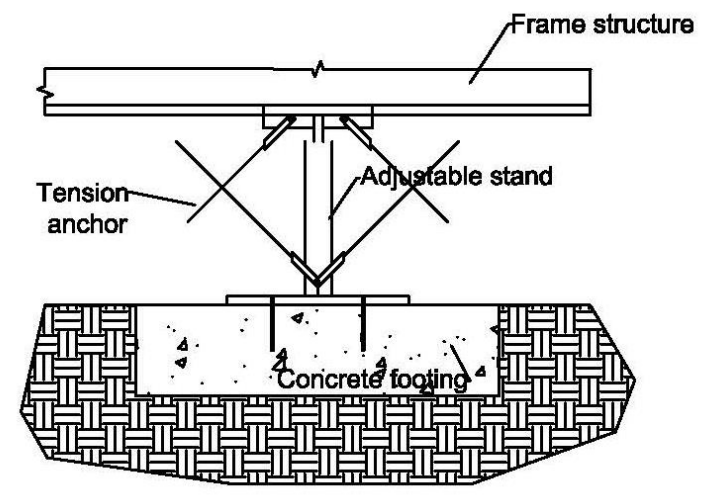

Figure 9. A permanent support column system embedded in a concrete footing with tension anchors (Adapted from Anchor Post Company, LLC).

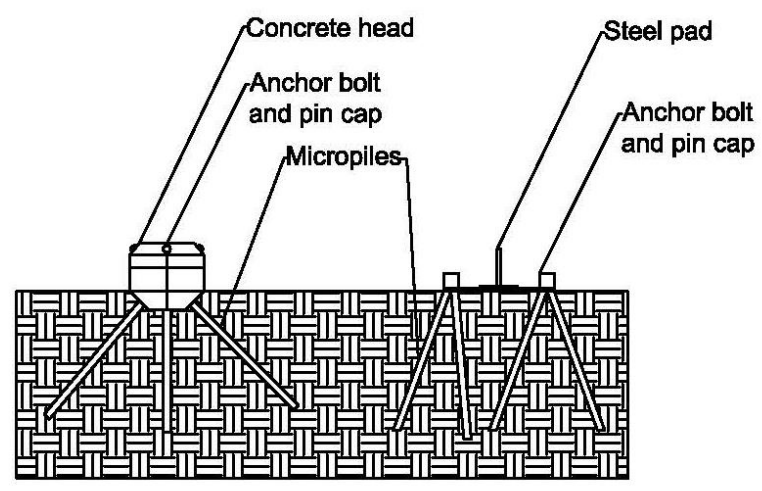

Figure 10. Micropiles with concrete head and anchor bolt and a reticulated micropiles with steel pad (Adapted from Diamond Pier and Surefoot). 


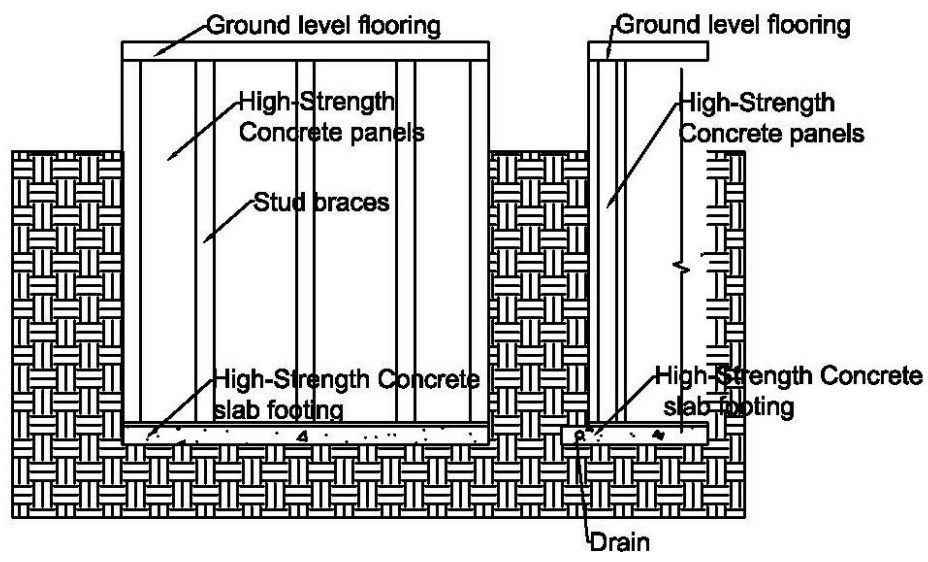

Figure 11. Prefabricated basement foundation using an integrated wall and footing system installed in an excavation (Adapted from Yu et al., 2008).

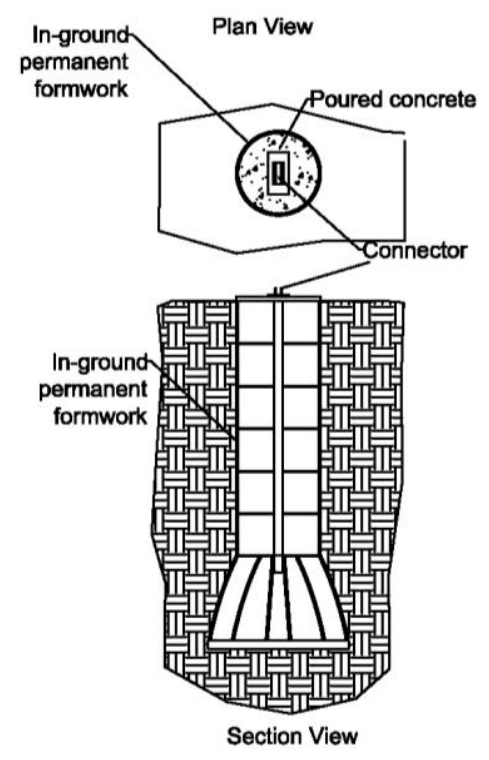

Figure 12. A permanent pier formwork with cast-in-place concrete (Adapted from WP Fail Safe Form Footer). 